\title{
(2) Deracemization of a Racemic Compound by Using Tailor-Made Additives
}

\author{
Anthonius H. J. Engwerda, Pim van Schayik, Henjo Jagtenberg, Hugo Meekes,* \\ Floris P. J. T. Rutjes, ${ }^{*}$ and Elias Vlieg ${ }^{[a]}$
}

Abstract: Viedma ripening is a process that combines abrasive grinding of a slurry of crystals with solutionphase racemization, resulting in solid-phase deracemization. One of the major disadvantages of Viedma ripening is that the desired compound needs to crystallize as a racemic conglomerate, accounting for only $5-10 \%$ of all chiral molecules. Herein, we show that use of a chiral additive causes deracemization under conditions, in which the compound normally crystallizes as a racemic compound. Although this concerns a single example, it is envisioned that through this new approach the scope of Viedma ripening can be significantly expanded.

Deracemization of chiral small molecules by using Viedma ripening has attracted much attention during the past decade. ${ }^{[1]}$ This method, which combines abrasive grinding of a slurry of crystals with solution-phase racemization, results in complete solid-phase deracemization (Figure $1 \mathrm{~b}$ ). The Viedma ripening process is operating when the compound crystallizes as a racemic conglomerate meaning that the enantiomers crystallize in separate crystals. Viedma was the first to demonstrate this method for the achiral inorganic salt sodium chlorate, which crystallizes in a chiral fashion. ${ }^{[2]}$ We and others have demonstrated that Viedma ripening can also be applied to intrinsically chiral organic molecules, such as amino acid derivatives, ${ }^{[3]}$ metal-organic complexes, ${ }^{[4]}$ and isoindolinones ${ }^{[5]}$ Although the outcome of a Viedma ripening experiment is in principle stochastic, it has been demonstrated that enantiopure additives (small amounts of a chiral compound that closely resembles the target compound) can be used to direct the outcome towards formation of a specific enantiomer. ${ }^{[6]}$

The requirement of formation of racemic conglomerates remains an inherent drawback for Viedma ripening. Because only $5-10 \%$ of all chiral molecules crystallize as conglomerate crystals, Viedma ripening is not suitable for the $90-95 \%$ of chiral compounds that crystallize as a racemic compound. One solu-

[a] A. H. J. Engwerda, P. van Schayik, H. Jagtenberg, Dr. H. Meekes, Prof. Dr. F. P. J. T. Rutjes, Prof. Dr. E. Vlieg

Radboud University Nijmegen, Nijmegen (The Netherlands)

E-mail:h.meekes@science.ru.nl floris.rutjes@ru.nl

(iD

Supporting information and the ORCID identification number(s) for the au-

thor(s) of this article can be found under:

https://doi.org/10.1002/chem.201706088.
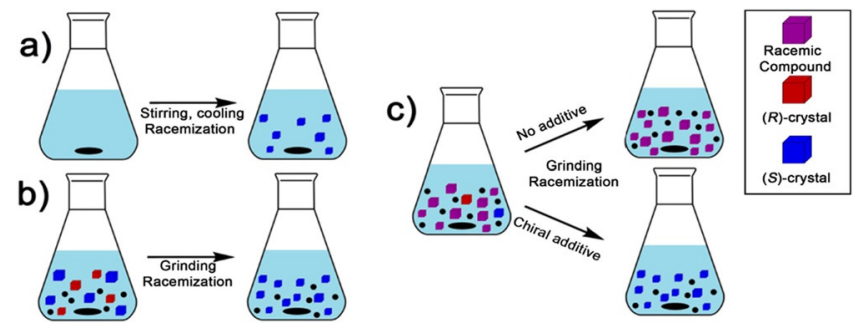

Figure 1. Conceptual approaches for deracemization of racemic conglomerates by a) total spontaneous resolution; b) Viedma ripening; c) this paper: deracemization of a suspension of a racemic compound by using chiral additives. In this scheme, the formation of enantiopure crystals is always represented by blue $(S)$-crystals.

tion to overcome this challenge is to modify the crystallization behavior of solids in such a way that conglomerate formation occurs. Examples include salt formation and screening multiple counterions for conglomerate formation. ${ }^{[7]}$ Alternatively, when deracemization of a certain class of neutral molecules is required, the problem can be solved by engaging in a library synthesis of derivatives to identify compounds that display conglomerate behavior. ${ }^{[8]}$ However, both approaches are certainly not generally applicable; for example, many compounds cannot form salts. Therefore, it would be beneficial to find approaches to apply attrition enhanced deracemization to racemic compounds without using any chemical modification. Herein, we show that this can be achieved by using tailormade chiral additives.

The concept of using additives in crystallization was applied long before Viedma ripening had been developed. Extensive studies were conducted by the group of Lahav, who focused on the resolution of conglomerates by using additives. ${ }^{[9]}$ They used enantiopure tailor-made additives that selectively bind to surfaces of crystals of the same chirality. This resulted in crystallization from solution of only the opposite enantiomer. The outcome of these additive-induced resolution experiments is therefore generally described by the Lahav rule of reversal; using a chiral additive results in preferential crystallization of the opposite chirality. ${ }^{[9,10]}$ This rule also holds when using additives in directing Viedma ripening processes. ${ }^{[6,11]}$ Note that in all these cases, additives were used to direct the outcome of the deracemization of a compound that crystallized as a racemic conglomerate.

When a compound crystallizes as a racemic compound, several methods for enantioenrichment have been reported. Klussman et al. showed that starting from nonracemic but also 
not enantiopure conditions, the eutectic composition of a compound can be used to create a very high solution enantiomeric excess (ee). ${ }^{[12]}$ When the eutectic composition is unfavorable, crystal engineering (by co-crystal formation) can be used to increase the ee. ${ }^{[13]}$ In addition, a few examples exist, in which a single enantiomer of a racemic compound could be crystallized from a saturated solution by using a chiral additive. The $\mathrm{HCl}$ salt of histidine crystallizes as a racemic dihydrate below $45^{\circ} \mathrm{C}$ and as a conglomerate monohydrate above this temperature. Using chiral polymeric additives, a single enantiomer could be crystallized under conditions, in which normally the racemic compound would be stable. ${ }^{[14]}$ A similar approach has been used for the resolution of calcium tartrate hydrate. ${ }^{[15]}$

In contrast to these examples, our experiments will start from a racemic suspension of crystals, seeded with just a few conglomerate crystals. In addition, the aim is not to separate the enantiomers, but completely deracemize the solid phase. It should be noted that both examples from the literature are unsuited for this additive-driven deracemization, because either racemization is very difficult (calcium tartrate), or the additive racemizes at similar conditions as the target molecule (histidine).

We now show that additives can be used to block the growth of the racemic compound of 1,1'-binaphthyl (compound 1), favoring the growth of a single enantiomer (Figure 2).

Because racemization of 1 happens spontaneously at the elevated temperatures that were used, deracemization could be achieved. In addition, the obtained handedness of the product could be directed by the chirality of the additive.

Binaphthyl (1, Figure 3) is an example of an atropisomer, a non-planar molecule that displays chirality through the hin-
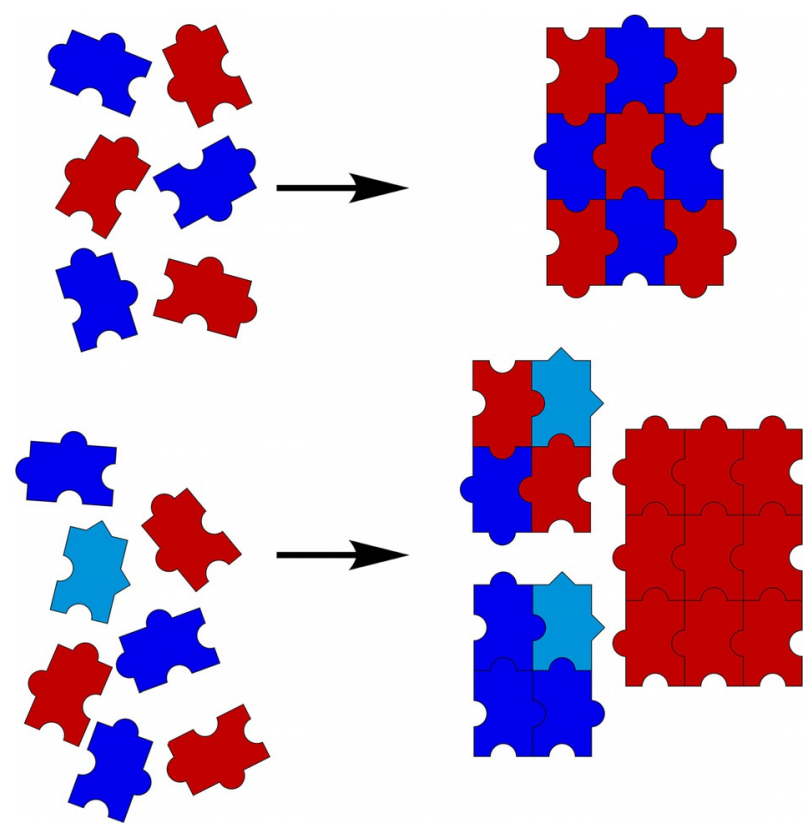

Figure 2. Chiral molecule that normally crystallizes as a racemic compound can, in the presence of a chiral additive (green blue, closely resembling one of the enantiomers), favor the preferential crystallization of a single enantiomer by blocking the growth of the other crystal structures.<smiles>c1ccc2c(-c3cccc4ccccc34)cccc2c1</smiles>

(S)-(+)-binaphthyl (S-1)<smiles>Oc1ccc2ccccc2c1-c1c(O)ccc2ccccc12</smiles>

(S)-(-)-BINOL $(\mathrm{S}-2)$<smiles>c1ccc2c(-c3cccc4ccccc34)cccc2c1</smiles>

$(R)-(-)$-binaphthyl (R-1)

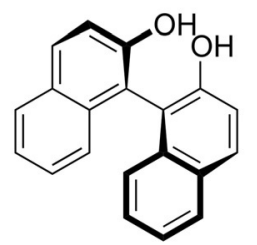

$(R)-(+)$-BINOL (R-2)
Figure 3. Both binaphthyl (1) and BINOL (2) are examples of atropisomers having an axis of chirality with hindered, temperature-dependent rotation around the chiral axis.

dered rotation around a single bond. ${ }^{[16]}$ Binaphthyl crystallizes as a racemic compound at room temperature, but converts into a conglomerate at temperatures above $85^{\circ} \mathrm{C} .{ }^{[17,18]}$ It racemizes readily at such temperatures $\left(t_{1 / 2}=14.5 \mathrm{~min}\right.$ in DMF at $50^{\circ} \mathrm{C}$ ), whereas racemization at room temperature is slow. ${ }^{[19]}$

Because binaphthyl (1) crystallizes as a racemic conglomerate above $85^{\circ} \mathrm{C}$, deracemization (by total spontaneous resolution) above this temperature can be achieved, as was shown by the groups of Pincock ${ }^{[18]}$ and Kondepudi. ${ }^{[20]}$ Below this temperature, we tested whether additives can be used to induce deracemization. As an additive, we chose BINOL (2), because it closely resembles binaphthyl (1), but does not racemize at temperatures below $100^{\circ} \mathrm{C} .^{[21]}$ The additive in these experiments was envisioned to operate through a kinetic pathway, blocking the growth of the racemic compound and one of the two conglomerate forms.

To study whether this additive could exert such an effect, a series of Ostwald ripening experiments were performed. For these experiments, nonane was selected as a solvent, because binaphthyl was very soluble in more polar solvent, resulting in a large loss of material during these experiments. In addition, it was determined that the half-life of racemization in nonane was appropriate for these experiments $\left(t_{1 / 2}=2.3 \mathrm{~min}\right.$ at $70^{\circ} \mathrm{C}$, see the Supporting Information). In these experiments, suspensions of equal amounts of racemic and conglomerate 1 (with or without additive) were gently stirred for two days. The solid phase was then characterized by using X-ray powder diffraction (XRPD), chiral HPLC, and scanning electron microscopy (SEM, Figure 4). Ostwald ripening without an additive at $90^{\circ} \mathrm{C}$ gave only octahedral crystals, corresponding to the racemic conglomerate. This indicates that the conglomerate is indeed the most stable phase at this temperature. In the presence of the enantiopure $(S)$-additive, similar size octahedrons were obtained containing only the (S)-enantiomer implying that deracemization had taken place during Ostwald ripening. In addi- 


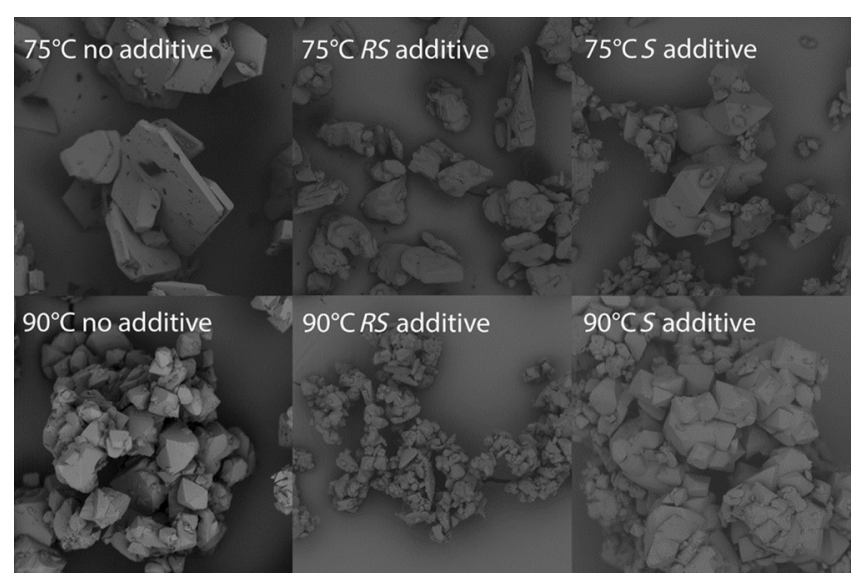

Figure 4. SEM images of crystals resulting from Ostwald ripening experiments of binaphthyl (1) in the presence and absence of $10 \%$ additive. The flat plates correspond to the racemic compound, the octahedrons to the conglomerate. In the presence of the racemic additive at $75^{\circ} \mathrm{C}$, a featureless material was obtained, which was shown by XRPD analysis to be the racemic compound.

tion, experiments were performed, in which both enantiomers of the additive were added. In these cases, the growth of all crystal forms (racemic conglomerate and racemic compound) was expected to be hampered. Indeed, when a racemic additive was used, the average size of these crystals was much smaller. Again, octahedrons of the racemic conglomerate were obtained, but now no deracemization had taken place. At temperatures of 80 and $75^{\circ} \mathrm{C}$, thin plates corresponding to the racemic compound were obtained in the absence of any additive. This proves that at these temperatures indeed the racemic compound is the most stable phase. However, in the presence of the enantiopure (S)-additive, again conglomerate octahedrons were obtained containing only the (S)-enantiomer. Growth of both the $(R)$-enantiomer and the racemic compound were hampered by the additive. When both enantiomers of the additive were added, the growth of all crystal forms was blocked. This resulted in a material with a featureless morphol- ogy, of which XRPD data showed that it corresponded to the racemic compound.

These observations indicate that the additive does indeed exhibit the intended kinetic effect on the binaphthyl crystals. Therefore, some larger-scale deracemization experiments were performed. In these experiments, glass beads were added to a suspension of crystals to create a Viedma ripening experiment. Because binaphthyl crystallizes as a racemic compound below $85^{\circ} \mathrm{C}$, experiments at such low temperatures were unsuccessful. Therefore, the additive approach was used to change the crystallization behavior from a racemic compound to a conglomerate.

When using this additive, deracemization of binaphthyl became possible under conditions, in which it is stable as a racemic compound (in the absence of additives). When using enantiopure additive 2 and a small amount of racemic conglomerate seed crystals, complete deracemization could be achieved within 12 hours (Figure $5 \mathrm{a}$ ). ${ }^{[22]}$ The resulting chirality could be directed by the handedness of the additive. Use of $(R)-\mathbf{2}$ always resulted in (R)-1, whereas adding (S)-2 resulted in (S)-1. This implies that the outcome of these experiments does not follow Lahav's rule of reversal, which is a discrepancy that we at this point cannot explain.

To further study the deracemization process, XRPD measurements were performed on samples taken during the deracemization experiments. These measurements revealed that the deracemization of 1 took place at the same rate as the conversion of the racemic compound into the conglomerate (Figure $5 \mathrm{~b}$ ). This gives some indication towards a possible mechanism of deracemization. During the grinding experiments, both the racemic compound and conglomerate dissolved resulting in (R)- and (S)-enantiomers in solution. The additive then hampered crystal growth as depicted in Figure 2. When using (S)-2 as an additive, the growth of both the racemic and conglomerate $(R)$-crystals were blocked (reverse rule of reversal). However, the (S)-enantiomers in solution could still be incorporated into the existing (S)-crystals. Grinding ensured a continuous increase in the number of these crystals. Because
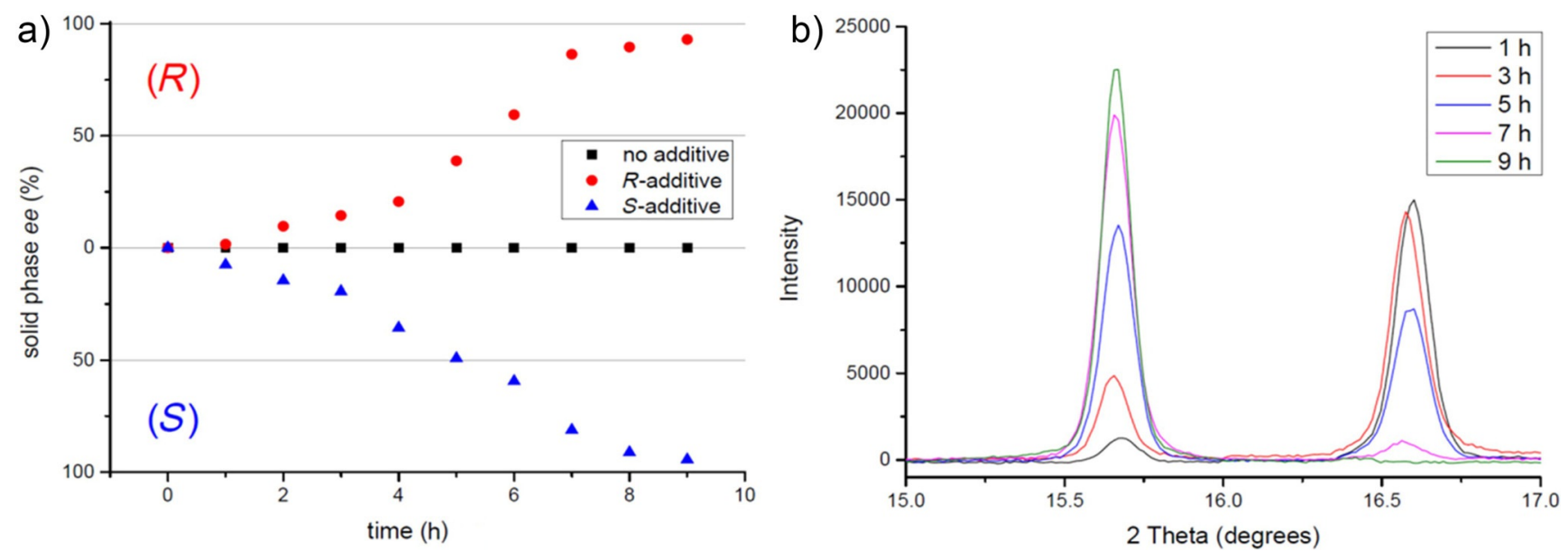

Figure 5. a) Deracemization curve of a grinding experiment of compound 1 at $80^{\circ} \mathrm{C}$ in the presence and absence of $10 \%$ enantiopure BINOL. b) The XRPD of the solid phase of 1 during these deracemization experiments showed the conversion from a racemic compound to a conglomerate. The peak at 15.7 degrees corresponds to the $\{102\}$ reflection of the conglomerate and the peak at 16.6 to the $\{11-1\}$ reflection of the racemic compound. 
racemization took place in solution, the $(R)$-enantiomers could be converted and consequently also be incorporated into the (S)-crystals. The racemic compound thus served as a gradual feed for the (S)-crystals in contrast to standard Viedma ripening, in which only the opposite enantiomers serve as feed. ${ }^{[23]}$

Both the concentration of the additive and the temperature of the experiment are of great influence on the deracemization rate (Figures 6 and 7). As was mentioned earlier, in the absence of the additive, no deracemization could be achieved at temperatures below $85^{\circ} \mathrm{C}$. When adding $2.5 \mathrm{~mol} \%$ of the additive, complete deracemization was achieved in around $40 \mathrm{~h}$ at a temperature of $80^{\circ} \mathrm{C}$. When increasing the additive concentration to $5 \%$, the deracemization time could even be decreased to around 15 hours. Because the solution was saturated with $5 \%$ additive, further increasing this concentration had no effect at either temperature. When repeating the same experiment at $75^{\circ} \mathrm{C}$, with $2.5 \%$ additive, no deracemization was observed. However, when increasing the additive concentration to $5 \%$, deracemization was achieved after 40 hours. These ex-

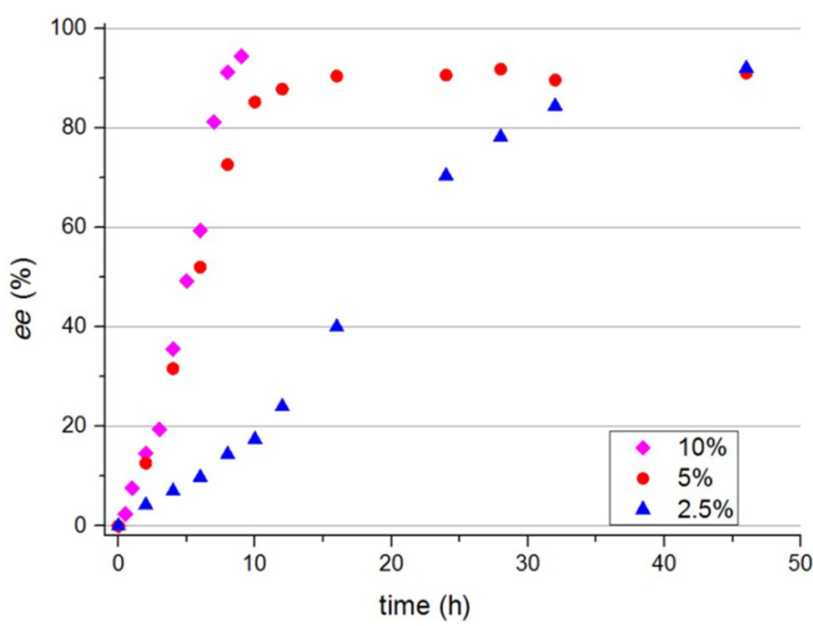

Figure 6. Effect of the additive concentration on the deracemization of compound 1 at $80^{\circ} \mathrm{C}$.

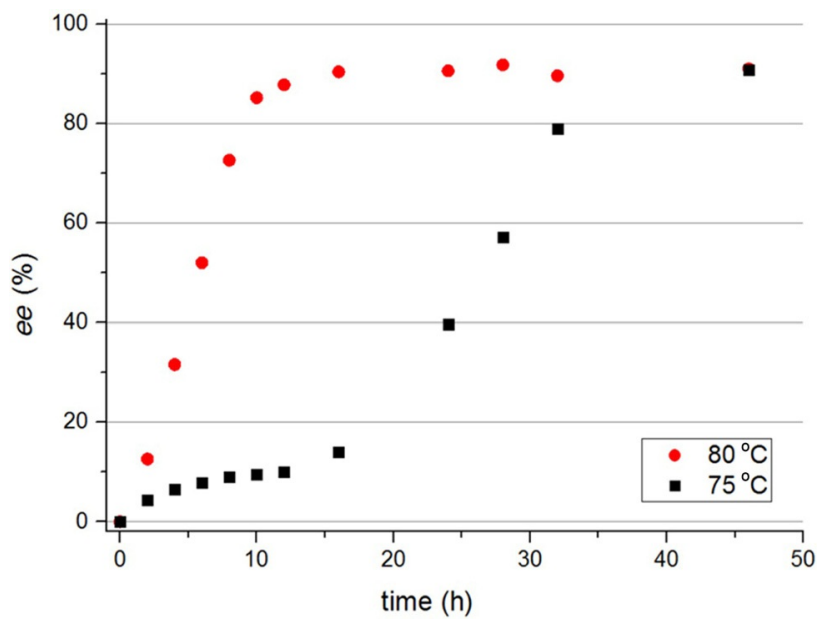

Figure 7. Deracemization of compound 1 in the presence of $5 \%$ additive (S)2 at 80 and $75^{\circ} \mathrm{C}$. periments suggest that the deracemization becomes more difficult when the system is further from the peritectic $\left(86^{\circ} \mathrm{C}\right)$, that is, when the racemic conglomerate becomes increasingly unstable. However, increased additive concentrations can be used to increase the range at which this approach is viable.

The main advantage of this additive approach to effect deracemization is that Viedma ripening is no longer restricted to the $5-10 \%$ of chiral molecules that crystallize as a racemic conglomerate. When a compound is stable as a racemic compound, deracemization can still be achieved by using appropriate chiral additives. In the present case, an appropriate additive was found by selecting a structurally closely related molecule that cannot be racemized under the conditions used. These additives cannot only be applied to peritectic systems, in which conglomerate and racemic compound are the stable phase at different temperatures, but potentially also for compounds for which the racemic compound is always the stable phase (as long as the energetic difference between both phases is not too large). Therefore, this kinetic approach expands the scope of attrition enhanced deracemization.

\section{Conflict of interest}

The authors declare no conflict of interest.

Keywords: additives • chirality - crystal growth deracemization - Viedma ripening

[1] L. C. Sögütoglu, R. R. E. Steendam, H. Meekes, E. Vlieg, F. P. J. T. Rutjes, Chem. Soc. Rev. 2015, 44, 6723-6732.

[2] C. Viedma, Phys. Rev. Lett. 2005, 94, 065504.

[3] W. L. Noorduin, T. Izumi, A. Millemaggi, M. Leeman, H. Meekes, W. J. P. Van Enckevort, R. M. Kellogg, B. Kaptein, E. Vlieg, D. G. Blackmond, J. Am. Chem. Soc. 2008, 130, 1158-1159; B. Kaptein, W. L. Noorduin, H. Meekes, W. J. P. van Enckevort, R. M. Kellogg, E. Vlieg, Angew. Chem. Int. Ed. 2008, 47, 7226-7229; Angew. Chem. 2008, 120, 7336-7339.

[4] P. M. Björemark, J. Jonsson, M. H. Hakansson, Chem. Eur. J. 2015, 21, $10630-10633$.

[5] R. R. E. Steendam, M. C. T. Brouwer, E. M. E. Huijs, M. W. Kulka, H. Meekes, W. J. P. van Enckevort, J. Raap, F. P. J. T. Rutjes, E. Vlieg, Chem. Eur. J. 2014, 20, 13527-13530.

[6] W. L. Noorduin, P. van der Asdonk, H. Meekes, W. J. P. van Enckevort, B. Kaptein, M. Leeman, R. M. Kellogg, E. Vlieg, Angew. Chem. Int. Ed. 2009, 48, 3278-3280; Angew. Chem. 2009, 121, 3328-3330.

[7] L. Spix, A. Alfring, H. Meekes, W. J. P. van Enckevort, E. Vlieg, Cryst. Growth Des. 2014, 14, 1744-1748.

[8] A. H. J. Engwerda, N. Koning, P. Tinnemans, H. Meekes, F. M. Bickelhaupt, F. P. J. T. Rutjes, E. Vlieg, Cryst. Growth Des. 2017, 17, 4454-4457.

[9] L. Addadi, Z. Berkovitchyellin, N. Domb, E. Gati, M. Lahav, L. Leiserowitz, Nature 1982, 296, 21 -26; L. Addadi, J. Vanmil, M. Lahav, J. Am. Chem. Soc. $1981,103,1249-1251$.

[10] L. Addadi, S. Weinstein, E. Gati, I. Weissbuch, M. Lahav, J. Am. Chem. Soc. 1982, 104, 4610-4617; I. Weissbuch, L. Addadi, M. Lahav, L. Leiserowitz, Science 1991, 253, 637-645.

[11] R. R. E. Steendam, B. Harmsen, H. Meekes, W. J. P. van Enckevort, B. Kaptein, R. M. Kellogg, J. Raap, F. P. J. T. Rutjes, E. Vlieg, Cryst. Growth Des. 2013, 13, 4776-4780; T. P. T. Nguyen, P. S. M. Cheung, L. Werber, J. Gagnon, R. Sivakumar, C. Lennox, A. Sossin, Y. Mastai, L. A. Cuccia, Chem. Commun. 2016, 52, 12626-12629.

[12] M. Klussmann, A. J. R. White, A. Armstrong, D. G. Blackmond, Angew. Chem. Int. Ed. 2006, 45, 7985-7989; Angew. Chem. 2006, 118, 81538157. 
[13] M. Klussmann, T. Izumi, A. J. P. White, A. Armstrong, D. G. Blackmond, J. Am. Chem. Soc. 2007, 129, 7657-7660.

[14] I. Weissbuch, D. Zbaida, L. Addadi, L. Leiserowitz, M. Lahav, J. Am. Chem. Soc. 1987, 109, 1869-1871.

[15] Y. Mastai, M. Sedlak, H. Colfen, M. Antonietti, Chem. Eur. J. 2002, 8, $2429-2437$

[16] M. Oki, Top. Stereochem. 1983, 14, 1-81.

[17] A transition temperature of $76^{\circ} \mathrm{C}$ is also reported, but we found $85^{\circ} \mathrm{C}$ to be the correct value.

[18] K. R. Wilson, R. E. Pincock, J. Am. Chem. Soc. 1975, 97, 1474-1478.

[19] A. S. Cooke (née Mellor), M. M. Harris, J. Chem. Soc. 1963, 2365-2373.

[20] D. K. Kondepudi, J. Laudadio, K. Asakura, J. Am. Chem. Soc. 1999, 121 $1448-1451$.

[21] E. P. Kyba, G. W. Gokel, F. Dejong, K. Koga, L. R. Sousa, M. G. Siegel, L. Kaplan, G. D. Y. Sogah, D. J. Cram, J. Org. Chem. 1977, 42, 4173-4184;
D. C. Patel, R. M. Woods, Z. S. Breitbach, A. Berthod, D. W. Armstrong, Tetrahedron: Asymmetry 2017, 28, 1557-1561.

[22] Although the ee appears to reach only $95 \%$ due to the sampling as explained in the ESI.

[23] W. L. Noorduin, B. Kaptein, H. Meekes, W. J. P. van Enckevort, R. M. Kellogg, E. Vlieg, Angew. Chem. Int. Ed. 2009, 48, 4581-4583; Angew. Chem. 2009, 121, 4651-4653; A. H. J. Engwerda, H. Meekes, B. Kaptein, F. P. J. T. Rutjes, E. Vlieg, Chem. Commun. 2016, 52, 12048-12051.

Manuscript received: December 22, 2017

Accepted manuscript online: January 12, 2018

Version of record online: February 1, 2018 